\title{
Reducing drug resistance should be the aim of therapies
}

\section{P. D. Gupta}

Former Director Grade Scientist, Centre for Cellular and Molecular Biology, Hyderabad, India

Corresponding Author: P. D. Gupta, Former Director Grade Scientist, Centre for Cellular and Molecular Biology, Hyderabad, India.

Received date: February 16 2021; Accepted date: March 15, 2021; Published date: March 18, 2021

Citation: P. D. Gupta. (2021) Reducing drug resistance should be the aim of therapies. Clinical Research and Clinical Trials. 3(2); DOI: $10.31579 / 2693-4779 / 028$

Copyright: Copyright (C) 2021 P. D. Gupta, This is an open access article distributed under the Creative Commons Attribution License, which permits unrestricted use, distribution, and reproduction in any medium, provided the original work is properly cited.

\begin{abstract}
Over the period, due to evolutionary constrains, gene mutations, changes in micro- and megaenvironment gave a tool to bacteria to adopt for survival in the hostile environment. When they are exposed with broad spectrum antibiotics, they have adopted to live and become resistant to antibiotics. In this review many preventive and curative strategies has been described to avoid antibiotics. These lines of treatments would not give chances to microbes to become drug resistant. "Prevention is better than cure" adopting this strategy we have described immunochemicals and many herbal medicines which will prevent infections. Also given importance to maintain proper balance of microbiota in the gut by replacement of the lost (may be due to many reasons) species which are considered necessary for maintaining a balance in bacterial population.
\end{abstract}

Keywords: drug resistance; spectrum antibiotics; immunochemicals; microbiota

\section{Introduction}

Omni present microorganisms can either be harmless to the host, or they can be highly

Dangerous to the core that they can take away the life of the host [1]. Over the period, due to evolutionary constrains, gene mutations, changes in micro- and mega- environment these microbiota change their morphological features to suit the environment. Some scientists even conjecture their presence on other planets and even in space because of their property that they can grow at high temperature without even photosynthesis [2,3]. Bacteria are the best example to adapt and survive

In hostile environment [4]. A systems perspective is needed to help understand the complex host-bacteria interactions and their association with pathophysiological phenotypes so that alterations in the composition of the gut microbiota in disease states can be reversed $[5,6]$ In addition to killing, antibiotics create imbalance between pathogenic and beneficial bacteria which causes more damage compared to fresh invasion of pathogens[5]. The need for novel antibiotics comes from the relatively high incidence of bacterial infection and the growing resistance of bacteria to conventional antibiotics [6]. Overuse of antibiotics have also created 'SuperBugs', because of these reasons antibiotic era is fast fading [7]. Consequently, new methods for reducing bacterial activity (and associated infections) are badly needed. More and more antibiotics becoming useless; many bacterial species have become drug resistant because of overdose of these drugs [7]. Not just because of only drug resistance, even imbalance of bacterial strains in microbiota can be the cause of serious health issues [5]. We must rebuild our defences against deadly bacteria by changing the strategise of the treatment; do we have any alternatives to existing antibiotics?

\section{Approaches towards Elimination of Antibiotics}

Now in order to avoid antibiotics generally 2 approaches have been adopted: Preventive and curative approaches. Immunochemicals and biologics. These are the products that are produced from living organisms or contain components of living organisms. Types of biologic drugs include vaccines, blood, blood components, cells, allergens, genes, tissues, and recombinant proteins. Antibody-based drugs offer new mechanisms of action and greater specificity. A vaccine is a biological preparation that provides active acquired immunity to a particular infectious disease [8]. A vaccine typically contains an agent that resembles a disease-causing microorganism and is often made from weakened or killed forms of the microbe, its toxins, or one of its surface proteins. A preventative vaccine is administered to a person who is free of the targeted infection. By introducing a part of the microbe or an inactive microbe (which acts like a decoy) into the body, the immune system reacts by producing antibodies. The most common and serious vaccine-preventable diseases tracked by the World Health Organization are: diphtheria, haemophilus influenzae serotype $b$ infection, hepatitis B, measles, meningitis, mumps, pertussis, poliomyelitis, rubella, tetanus, tuberculosis, and yellow fever.

The bacterial genetic material (DNA and / or RNA) is attacked by synthetic peptide-conjugated phosphorodiamidate morpholino oligomer (PPMO) (Genetical approach), or bacteria can be killed by specific viruses, or by restoration of missing components of the flora from fecal microbiota to balance the missing population and by recently developed 
[5,9]. Nanotechnologal approach where many types of nanoparticles and nanocomposites are used to target bacteria as an alternative to antibiotics [10]. Many traditional organic substances such as Manuka honey, tea tree and clove oil, and curcumin are also in vogue. Recently, researchers have found some alternatives to attack bacteria without using antibiotics [11].

\section{Faecal transplants}

Transplantation of faces from a healthy donor into another person to restore the balance of bacteria in their gut. Faecal transplants may help treat gastrointestinal infections causing severe diarrhoea and other conditions. A difficult-to-treat life-threatening bacterial infection of Clostridium difficile, also been treated with faecal, most patients' symptoms went away within 48 hours of the procedure, In a 2013 study,[12] researchers processed donor faecal matter until it contained only bacteria that they could put in a pill, and found that the pills were well tolerated by patients with Clostridium difficile. Five out of nine patients who received faecal bacteria were cured immediately of their infections, compared to five of 11 in the group getting antibiotics. Three of the four remaining patients who got faecal bacteria then got antibiotics; two were cured within days [13-17].

\section{Exercise}

There are trillions of microscopic organisms in the gut that play a crucial role in our overall health and function of the body. During moderate exercise, immune cells circulate through the body more quickly and are better able to kill bacteria and viruses. Cortisol and adrenaline, known as the stress hormones, raise blood pressure and cholesterol levels and suppress the immune system. Research showed that exercise also improves the gut bacteria. Exercise can change the composition of population of gut microbiome.

To measure the benefit of exercise against inflammation in the gut, Woods and colleagues performed the first exercise fecal microbiome transplant in mice and published the results in 2017. They took faecal matter from mice that exercised and those that didn't and transferred the material into germ-free mice. Then, once the microbiota had established itself in the recipients, the team gave the animals' drugs, inducing extreme inflammation in the colon. Mice that received gut microbes from active donor's loss less body weight and had fewer symptoms of inflammatory disease compared with mice that received microbes from sedentary animals [18]. Whether a similar protocol could help people suffering from irritable bowel syndrome - marked by persistent inflammation — remains to be tested.

Therefore the exercise can be used as a treatment to maintain the balance of the microflora or to rebalance his eventual dysbiosis, thus obtaining an improvement of the health status. Nevertheless further studies are needed to fully understand the mechanisms that determine changes in the composition and functions of the microflora caused by exercise and all their related effects. Although exercise-altered microbiota could be an approach for the treatment of diseases associated with alterations of the intestinal microflora, very few studies have investigated the beneficial effects of exercise on the microflora composition in relation to disease [19].

\section{Genetic approach}

This approach is very effective. The bacterial genetic materi-al (DNA and/or RNA) is attacked by synthetic peptide-conjugated phosphorodiamidate morpholino oligomer (PPMO) [9]. This compound has been proved to be the bacteria's new worst enemy; even superbug Clostridium difficile is killed by this newly synthesized compound. Unlike antibiotics, PPMO can silence specific genetic targets by disrupting the bacterial gene's synthesizing capacity. Although, there is no issues about the efficacy of PPMO, issues of its toxicity need to be addressed in further testing before it can be used in humans. The mechanism that PPMOs use to kill bacteria is revolutionary and therefore bacteria can not develop resistance to this; as they have developed for conventional antibiotics [9].

\section{Viral attack}

Superbug Clostridium difficile is one of the natural microbes found in the gut, but chronic antibiotic use can make it go haywire. It's also one of the many superbugs turning up at hospitals. It causes many deaths and hospitalizations among humans worldwide. Viruses that eat bacteria, to specifically target C. diff. They work by attaching to bacteria as a host, injecting their DNA-which replicates-and causing the bacterial cell to burst open. Researchers say these phages are effective against 90 percent of the most clinically relevant C. Diff strains in the United Kingdom. AmpliPhi is funding the development of these C. diff phages and hopes to have a mixture ready for clinical trials soon [20].

\section{Phage therapy}

Phages, short for bacteriophages, are bacteria-specific viruses that have been used as a treatment against pathogens with an estimated 10311032 phages in the world at any given time [2], they make up the most abundant biological entity on Earth and play a crucial role in regulating bacterial populations. Conventionally, phage therapy relies on the use of naturally-occurring phages to infect and lyse bacteria at the site of infection [21].

Phage therapy is widely being reconsidered as an alternative to antibiotics. Currently, bioengineered phages and purified phage lytic proteins specifically against multidrug-resistant bacterial infections are used, as either an alternative or a supplement to antibiotic treatments. Although much is still unknown about the interactions between phage, bacteria, and human host, the time to take phage therapy seriously seems to be rapidly approaching [22]. 


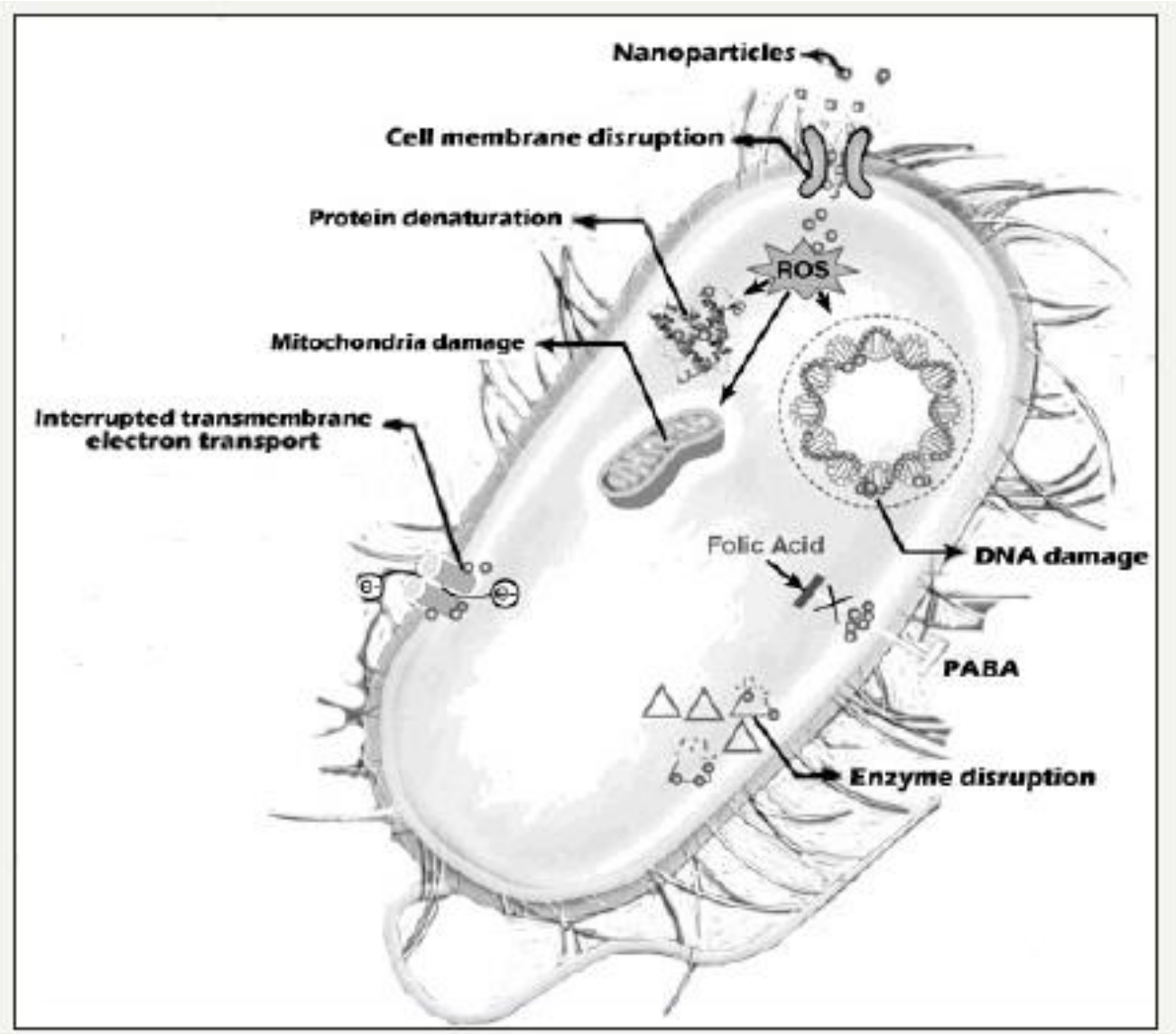

Figure 1: Showing various mechanism of action of bactericidal drugs for killing bacteria. Adopted from (Gupta and Asha, 7)

\section{CRISPR Technology}

A new CRISPR tool could be instrumental in preventing pathogenesis of human bacterial infections and plasmid-borne antibiotic resistance genes and virulence determinants. To achieve this system, researchers developed a proactive genetic system, or ProAG, that uses self-copying mechanisms to scrub antibiotic resistance. Plasmid-encoded antibiotic resistance determinants can be targeted by CRISPR gRNA/Cas 9 systems in bacteria Genes conferring antibiotic resistance are often found on plasmids, circular forms of DNA that can replicate independently of the bacterial genome. Amplification effects of these plasmids can lead to the transfer of antibiotic resistance among bacteria. Recently Valderrama et al [23] .Have developed several cut-and-destroy methods but have had only moderate success with them. The system relies on a self-amplifying "editing" mechanism that increases its efficiency through a positive feedback loop. The success of this system is attributed to the precise insertion of the gRNA into the targeted cleavage site with appropriate cargo sequences, which reduced antibiotic-resistant colonies.

While Pro-AG is not yet ready for treating patients, a human delivery system carrying Pro-AG could be deployed to address conditions such as cystic fibrosis, chronic urinary infections, tuberculosis and infections associated with resistant biofilms that pose difficult challenges in hospital settings "It's possible that this attachment is a common feature in many type IV pili expressing enteropathogens such as Vibrio cholerae and constitutes a new therapeutic target against such bacterial pathogens."

Their research results will lead to the development of not only new vaccines for Enterotoxigenic E. coli (ETEC), but also anti-adhesion agents for preventing the binding of proteins implicated in bacterial attachment. Anti-adhesion agents can rinse pathogenic bacteria out from the body without destroying them, so there is no danger of producing drug-resistant bacteria. These agents, once developed, will act as a novel treatment approach that may serve as an alternative to antibiotics.

\section{Nanotechnology}

The need for novel antibiotics comes from the relatively high incidence of bacterial infection and the growing resistance of bacteria to conventional antibiotics. Consequently, new methods for reducing bacteria activity (and associated infections) are badly needed Nanotechnology may be particularly advantageous in treating bacterial infections. Nanoparticles (NPs) are increasingly used to target bacteria as an alternative to antibiotics. . The antibacterial mechanisms of NPs are poorly understood, but the currently accepted mechanisms include oxidative stress induction, metal ion release, and non-oxidative mechanisms. The multiple simultaneous mechanisms of action against microbes would require multiple simultaneous gene mutations in the same bacterial cell for antibacterial resistance to develop; therefore, it is difficult for bacterial cells to become resistant to NPs [24,25].

\section{Many traditional organic substances}

Long ago In Ayurveda herbal medicines were used in addition to some animal product and some minerals (ashes) to control all sorts of diseases [11]. They used the same herb for preventing as well curative purposes depending on doses. In the middle ages many infectious diseases were conquered through the discovery of antibiotics and antiviral agents. However, due to immergence of the antibiotic-resistant strains and mutant microorganisms that are more powerful than the existing ones in recent times, again natural products have been as widely used as chemical drugs against infectious diseases. However, since natural products are 
the by-products of empirical medicine, they lack scientific validation. Currently, various scientific experiments are being conducted to fill this gap by evaluating the efficacy of natural product $[26,-28]$.

\section{Manuka}

honey is sometimes referred to as medicinal honey because it has a high antibacterial activity and has been shown to be good for wound healing and can help to relieve sore throats, mouth ulcers, sore gums and possibly indigestion," Debenham explained. Tea tree oil is an essential oil distilled from the leaves of the native Australian plant Melaleuca alternifolia. In recent decades, its popularity has grown in other areas of the world as an alternative and complementary treatment. Today, tea tree oil is commonly found in cosmetics, topical medicines, and household products [29]. Tea tree oil is best known for its antibacterial, Antiinflammatory and antifungal activity [30, 31]. Other research indicates that a type of bacteria associated with bad breath may be treated with tea tree oil and alpha-bisabolol, the active component in chamomile [32].

\section{Fights infections}

Traditionally Clove oil, has been used for easing digestive upset, relieving pain, and helping with respiratory conditions. Research has found that clove oil may have benefits for dental and topical applications, for treating infections, and even fighting cancer [33]. Blessed with a multitude of antiseptic properties, clove oil can be used to treat cuts, wounds, fungal infections, insect bites and even stings. However, direct application of clove oil may prove harmful. If the wound is too sore, it is advisable to dilute clove oil by adding almond or coconut oil. These carrier oils will prevent your sensitive skin from burns that can be caused by direct application of clove oil.

\section{Curcumin}

Turmeric and especially its most active compound have many scientifically-proven health benefits, such as the potential to prevent heart disease, Alzheimer's and cancer [34]. It's a potent anti-inflammatory and antioxidant and may also help improve symptoms of depression and arthritis. Turmeric and especially its most active compound curcumin have many scientifically-proven health benefits, such as the potential to prevent heart disease, Alzheimer's and cancer. It's a potent anti-inflammatory and antioxidant and may also help improve symptoms of depression and arthritis.

\section{Conclusions}

Microorganisms are much simpler than human being, but Nature has given certain special features to them. Bacteria and other microorganisms divide rapidly, which increases the likelihood for higher mutation rate in turn when they are exposed to antibiotics there are fair chances to evolve antibiotic-resistant mutants. Resistance is multifaceted and therefore microorganisms have ample opportunity to evolve and become resistant to entire antibiotic classes over the period. In addition, the misuse of antibiotics to treat viral diseases (e.g., the common cold) unnecessarily exposes patients and their bacteria to antibiotics and fails to treat the actual disease being experienced. This ease of access only increases exposure and subsequently the risk of resistance. Broad-spectrum antibiotics: they kill not only harmful pathogens, but "good" bacteria that make up the microbiome within humans. Doing so results in the development of resistance in the target pathogen as well as the members of healthy microbiome, which can then transfer resistance to pathogens they encounter, further spreading the problem. Killing of the healthy microbiome has been linked not only to the development of Clostridium difficile diarrhea but also diabetes, obesity, immune defects, and antibiotic resistance spread through gene transfer

In order to resolve these issues, we have to avoid use of broad-spectrum antibiotics and adopt the Pathogen-specific strategies. Even before this, as discussed, we should give more stress to herbal medicines to prevent infections, this way we will be less exposed to antibiotics.

\section{References}

1. M Smith, E Habte-Gabr (1977) Life-threatening Infections: How to Choose the Right Antibiotics Geriatrics ;32(3):83-86.

2. Robert F. Service (2019) This microbe no longer needs to eat food to grow, thanks to a bit of genetic engineering doi:10.1126/science.aba3784

3. P D Gupta (2018) Bacteria: The powerful creatures J Cell Tissue Res 18 (3), 6555-6558

4. F. Seigle-Murandi, P. Guiraud, J. Croize, E. Falsen, and K. L. ErikssonBacteria (1996) Are Omnipresent on Phanerochaete chrysosporium Burdsall. Appl Environ Microbiol. 62(7): 24772481

5. Sawicka B, Johar K, Sood PP, Gupta PD (2017) Imbalance of gut microbiota induces cancer. J Cell Tissue Res 17(2): 6073-6084.

6. Higgins CF (2007) Multiple molecular mechanisms for multidrug resistance transporters. Nature 446(7137): 749-757

7. P D Gupta, AK Asha (2018) The Price we Pay for Overdose of Antibiotics: Is there any Alternative? Infect Dis 197 (3), 435-438

8. C. Challener, (2018) Fighting Bacterial Resistance with Biologics," Pharmaceutical Technology 42 (12).

9. Oregon State University (2013) beyond antibiotics: 'PPMOs' offer new approach to bacterial infection, other diseases. Science Daily, USA.

10. Nam S, Brian DC, Christopher DD, Krystal RF (2016) Silvercotton nanocomposites: Nano-design of microfibrillar structure causes morphological changes and increased tenacity. Scientific Reports 6, Article number: 37320.

11. Mishra, S.A. \& Vibrachita, V. (2019): RasaratnaSamuchch-aya, published by Chaukambika Orientalia, Varanasi, India. www.hopkinsmedicine.org, advanced_endoscopy Fecal Transplantation (Bacteriotherapy) $\mid$ Johns Hopkins ...

12. Drekonja D, Reich J, Gezahegn S, Greer N, Shaukat A, et al. (2015) Fecal microbiota transplantation for clostridium difficile infection. A systematic review. Annals of Internal Medicine 162(9): 630-638.

13. Smith PA (2014) A new kind of transplant bank. The New York Times, USA.

14. Chang JY, Antopoulos DA, Kalra A (2008) Decreased diversity of the fecal microbiome in recurrent Clostridium difficileassociated diarrhea. J Infect Dis 197(3): 435-438.

15. Khoruts A, Dicksved J, Jansson JK (2010) Changes in the composition of the human fecal microbiome after bacteriotherapy for recurrent Clostridium difficile-associated diarrhea. J Clin Gastroenterol 44(5): 354-360.

16. Frederik E. et al. (2018) Fecal Microbiota Transplantation for Primary Clostridium difficile Infection N Engl J Med; 378:25352536

17. Vincenzo Monda, Ines Villano, Antonietta Messina, et al (2015) modifies the Gut Microbiota with Positive Health Effects. Oxid Med Cell Longev.; 2017: 3831972.

18. Allen J. M., Miller M. E. B., Pence B. D. Voluntary and forced exercise differentially alters the gut microbiome in C57BL/6J Mice. Journal of Applied Physiology. ;118(8):1059-10664

19. Janet YN, Janice S, Katherine RH, Anthony MB, Przemysław T, et al. (2016) Bacteriophage combinations significantly reduce clostridium difficile growth in vitro and proliferation in vivo. Antimicrobial Agents and Chemotherapy 60(2): 968.

20. Derek M Lin, Britt Koskella, and Henry C Lin (2017) Phage therapy: An alternative to antibiotics in the age of multi-drug resistanceWorld J Gastrointest Pharmacol Ther.8(3): 162-173. 
21. Lin DM, Koskella B, Lin HC. (2017) Phage therapy: an alternative to antibiotics in the age of multi-drug resistance. World $\mathbf{J}$ Gastrointest Pharmacol Ther.;8:162-173.

22. Valderrama, J.A., Kulkarni, S.S., Nizet, V. et al. (2019) A bacterial gene-drive system efficiently edits and inactivates a high copy number antibiotic resistance locus. Nat Commun 10, 5726.

23. Linlin Wang, Chen $\mathrm{Hu}, 2$, Longquan Shao (2017) The antimicrobial activity of nanoparticles: present situation and prospects for the future Int J Nanomedicine 12 1227-1249

24. Justin T Seil 1, Thomas J Webster (2012) Antimicrobial Applications of Nanotechnology: Methods and Literature Int $\mathbf{J}$ Nanomedicine 2012:7 2767-2781

25. Kang-Ju Kim, Xiangqian Liu, Takashi Komabayashi, Seung-Il Jeong, and Serkan Selli (2016) Natural Products for Infectious Diseases Evid Based Complement Alternat Med.; 2016: 9459047.

26. PD Gupta, R Babu, PV Deshmukh Antibacterial activity of 6 Indian medicinal plants against bacterial pathogens isolated from various skin ailments.Asian Journal of Experimental Biological Sciences 4 (3), 336-344
27. Akram M. Salam and Cassandra L. Quave (2018) Opportunities for plant natural products in infection control Curr Opin Microbiol. 45: 189-194.

28. S D Cox 1, C M Mann, J L Markham, H C Bell, J E Gustafson, J R Warmington, S G Wyllie (2000). The Mode of Antimicrobial Action of the Essential Oil of Melaleuca Alternifolia (Tea Tree Oil) J Appl Microbiol. ;88(1):170-175.

29. C. F. Carson K. A. Hammer,and T. V. Riley (2006) Melaleuca alternifolia (Tea Tree) Oil: a Review of Antimicrobial and Other Medicinal Properties . Clin Microbiol Rev. 19(1): 50-62.

30. Janmejai K Srivastava, Eswar Shankar, and Sanjay Gupta Chamomile: (2010) A herbal medicine of the past with bright futureMol Med Report. 3(6): 895-901.

31. Sumita Halder, Ashish K Mehta, Pramod K Mediratta, Krishna K Sharma (2011).Essential oil of clove (Eugenia caryophyllata) augments the humoral immune response but decreases cell mediated immunity. Phytother Res. 25(8):1254-6.

32. Adapala, N., Chan, M. (2008) Long-term use of an antiinflammatory, curcumin, suppressed type 1 immunity and exacerbated visceral leishmaniasis in a chronic experimental model. Lab Invest 88, 1329-1339.

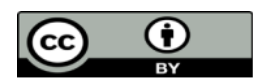

This work is licensed under Creative Commons Attribution 4.0 License

To Submit Your Article Click Here: Submit Manuscript

DOI: $10.31579 / 2693-4779 / 028$
Ready to submit your research? Choose Auctores and benefit from:

* fast, convenient online submission

* rigorous peer review by experienced research in your field

* rapid publication on acceptance

* authors retain copyrights

* unique DOI for all articles

* immediate, unrestricted online access

At Auctores, research is always in progress.

Learn more www.auctoresonline.org/journals/clinical-research-andclinical-trials- 